\title{
Noise in Classrooms Data Set
}

\author{
Bernardo Tabuenca \\ Open Universiteit, The Netherlands \\ bernardo.tabuenca@ou.nl \\ Dirk Börner \\ Open Universiteit, The Netherlands \\ dirk.boerner@ou.nl
}

\begin{abstract}
We present a data set comprising noise samples collected during 26 sessions of the subject "Technology" of Secondary Education studies with a mobile device. The data set includes rich metadata with the aim to facilitate the correlation with further studies, namely, type of session (i.e. traditional face-to-face lecture, collaborative workshop session, individual computer session), the number of students participating in the session, the percentage of male/female students, the mean age of the students, timestamp when the sample was collected, language of the session, country, city and location where it took place. The data is shared in different format to facilitate its management across platforms.
\end{abstract}

Keywords: Noise, classroom, sensor, mobile technology

\section{INTRODUCTION}

Recent work reviews experimental studies addressing the impact of noise exposure concluding negative effects on speech perception and listening comprehension in the classroom. Indoor noise and reverberation in classroom settings are associated with poorer performance of the children. These effects are more pronounced in children as compared to adults (Klatte, Bergström, \& Lachmann, 2013).

However, most of the classrooms are not equipped with sensor technology to warn the students/teacher about how appropriate the actual noise levels are. The trend to use interconnected artefacts (Internet of Things) in organizations as well as in educational settings (Johnson, Brown, Cummins, \& Estrada, 2012), and the current status quo in which every student/teacher owns a smartphone, enables the implementation of easy solutions to cover this gap.

Current research investigates how to provide real-time feedback on the levels of noise to moderate suitable levels of noise in classroom towards learning (Tabuenca, Börner, \& Specht, n.d.). A mobile device with the Noise Mirror installed in it (See Figure 1) collects the noise samples with the configured frequency (e.g. every second), providing real time feedback, and suitable chart visualizations so these samples can be analysed in the mobile. Alternatively, these samples can be exported to CSV file concluding in datasets analogous to the one presented in this manuscript. These dataset can be later on 
analysed with the aim to contrast noise means between different groups or treatments (See Figure 2), evolution of the noise along the session (See Figure 3) or correlate the noise levels with the number of participants, the mean age of the students, the teaching style from the lecturer or the day of the country where the session took place (See Figure 4).

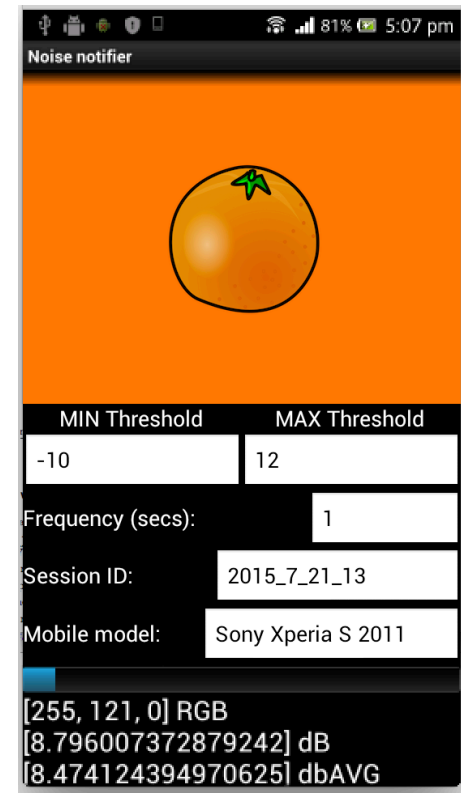

Figure 1: The Noise Mirror. Sampling noise via mobile device

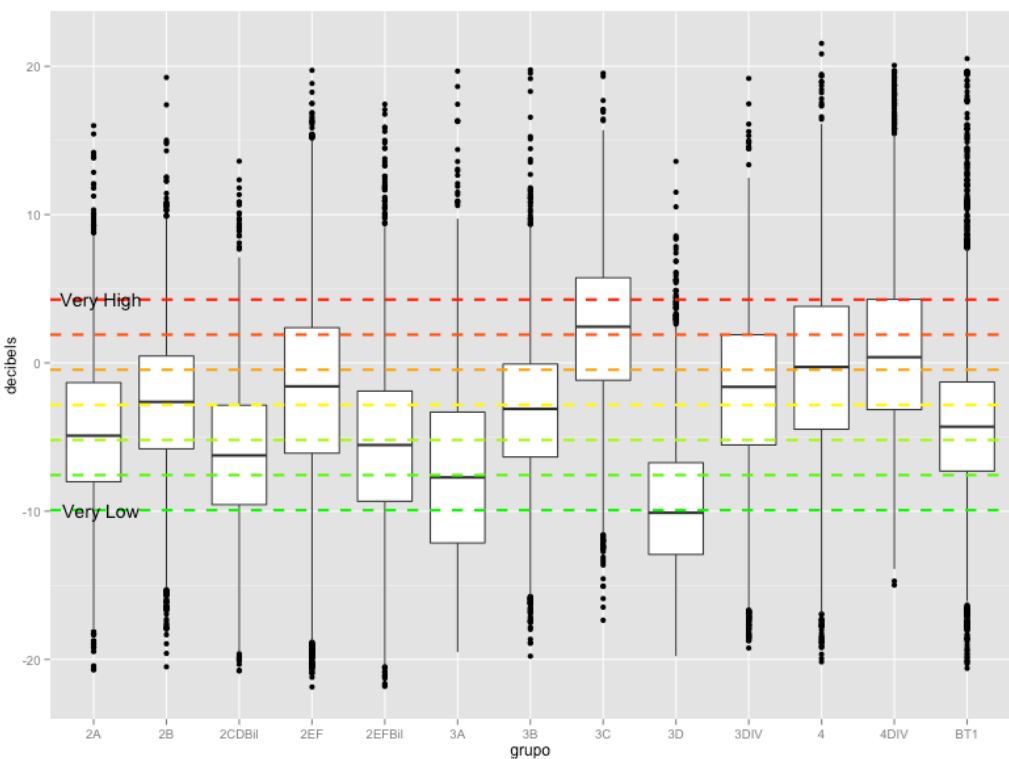

Figure 2: Noise contrasts for different groups and treatments

Figure 1: The Noise Mirror. Sampling noise via mobile device Figure 2: Noise contrasts for different groups and treatments

\section{THE DATA SET}

This dataset comprises 60612 noise samples collected from 26 sessions (Mean 2331 samples per session) in May 2015 at the secondary school in Spain. A total of 398 students (Mean 14,5 students per session) participated in these sessions from which $49 \%$ were female, and the age of the students fluctuated from 13 to 18 years old.

This study aims at identifying how students and teachers change their behavior with regard to the noise level in the classroom, depending on whether they have a visual feedback (Börner, Tabuenca, Storm, Happe, \& Specht, 2015) providing information on the current level of noise in the classroom. Hence, this research explores the behavior from both teachers and students, but also measures how accurate are the estimations of perceived noise from teachers and students with respect to the objective measure taken via mobile device.

This dataset can be potentially used for correlation with further groups that differ in: 
(2016). Noise in the classroom data set. Journal of Learning Analytics, 3(2), 325-329. http://dx.doi.org/10.18608/jla.2016.32.19

- $\quad$ Mean age of the students.

- $\quad$ Number of students participating in the classroom (male/female).

- $\quad$ Location. Country/region where the session takes place.

- Mobile device used to collect the data. Smartphones are equipped with different microphones.

- $\quad$ Time of the day and day of the week when the session takes place.

- $\quad$ Teaching style \& session type. Noise might be moderated by the teacher that is leading the lecture, the topic of the subject or the type of activities accomplished during the session (e.g. collaborative, individual, cooperative).

\subsection{Creator / Owner}

The first author of this manuscript used the tool illustrated in Figure 1 to collect and export the samples comprising this dataset.

The dataset has been licensed Open access - Unrestricted access (CCO Waiver No Rights Reserved https://creativecommons.org/about/cc0)

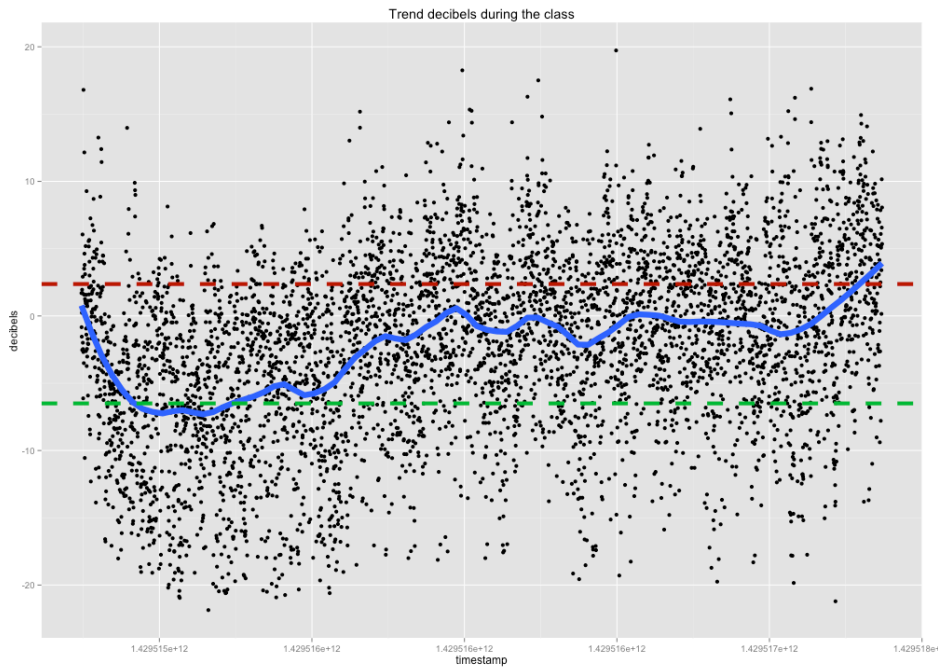

Figure 3: Noise evolution along the session

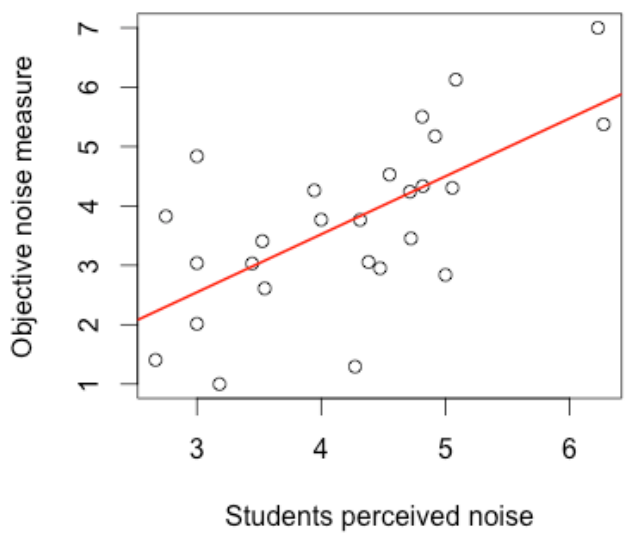

Figure 4: Noise correlation analysis

\subsection{Details}

The dataset (Tabuenca, 2015) has been stored in DANS-EASY, a sustainable repository for archiving or research data. It can be accessed using the searching tool of the platform looking for the string "Noise in classrooms data set" or directly downloading it from the following reference:

ISSN 1929-7750 (online). The Journal of Learning Analytics works under a Creative Commons License, Attribution - NonCommercial-NoDerivs 3.0 Unported (CC BY-NC-ND 3.0) 
Tabuenca, Dr. B. (Open University of The Netherlands) (2015): Noise in classrooms data set. DANS. http://dx.doi.org/10.17026/dans-x4j-p9zf

\section{$2.3 \quad$ Format}

The data set is available in the standard CSV format.

Table 1 Columns of CSV file with answers.

\begin{tabular}{|c|c|}
\hline Column & Description \\
\hline Tag & $\begin{array}{l}\text { Tag that identifies the session, classroom, treatment or group in which } \\
\text { the sample is taken. e.g. [2015_3_16_9_Treatment2] }\end{array}$ \\
\hline Decibels & Decibels collected via mobile device. e.g. [5.352124803] \\
\hline Timestamp & $\begin{array}{l}\text { Timestamp in milliseconds when the sample was taken. e.g. } \\
\text { [1429168968116] would be Thu, } 16 \mathrm{Apr} 2015 \text { 07:22:48 GMT }\end{array}$ \\
\hline Num_students & Number of students participating in the session. e.g. [25] \\
\hline Num_students_female & Number of female students participating in the session. e.g. [12] \\
\hline Session_type & $\begin{array}{l}\text { Type of session. i.e. traditional face-to-face lecture ("L"), collaborative } \\
\text { workshop atelier ("W"), individual computer session ("C"). This field can } \\
\text { be aggregated means that the session was split into two activities: lecture } \\
\text { and computer activities. e.g. [ }[\mathrm{CC}]\end{array}$ \\
\hline Language & Language in which the session was held. e.g.[ES] \\
\hline Location & $\begin{array}{l}\text { Town, city, region where the session took place. e.g. [Calatayud; } \\
\text { Zaragoza; Spain] }\end{array}$ \\
\hline Latitude & Latitude coordinates where the samples were taken. e.g [41.357734] \\
\hline Longitude & Longitude coordinates where the samples were taken. e.g [-1.636562] \\
\hline Device & Device used to collect the noise samples e.g. [Sony Xperia S] \\
\hline
\end{tabular}

\section{ETHICAL AND PRIVACY CONSIDERATIONS}

The dataset has been anonymised. 


\section{ACKNOWLEDGEMENTS}

The authors would like to thank Ana María Célix, Ana Sanz, Beatriz Ramón, and María Pilar Álvarez (in alphabetical order) for their contribution in this research

\section{REFERENCES}

Börner, D., Tabuenca, B., Storm, J., Happe, S., \& Specht, M. (2015). Tangible Interactive Ambient Display Prototypes to Support Learning Scenarios. Proceedings of the Ninth International Conference on Tangible, Embedded, and Embodied Interaction (TEI' 15), 721-726. http://dx.doi.org/10.1145/2677199.2687908

Johnson, L., Brown, S., Cummins, M., \& Estrada, V. (2012). The Technology Outlook for STEM+ Education 2012-2017: An NMC Horizon Report Sector Analysis. Austin, TX: The New Media Consortium. Retrieved from http://www.editlib.org/p/48971/

Klatte, M., Bergström, K., \& Lachmann, T. (2013). Does noise affect learning? A short review on noise effects on cognitive performance in children. Frontiers in Psychology, 4, 578. http://dx.doi.org/10.3389/fpsyg.2013.00578

Tabuenca, B. (2015). Noise in Classrooms data set [Data Set]. Heerlen: DANS. http://dx.doi.org/10.17026/dans-x4j-p9zf

Tabuenca, B., Börner, D., \& Specht, M. (n.d.). The Noise Mirror: Observation and accuracy of the measures in classroom settings. Unpublished manuscript, under review. 